\title{
CONSTRUÇÃO, USO E AVALIAÇÃO DE UMA PLATAFORMA PARA PUBLICAÇÃO DE WEBQUEST NO SENAI/SC EM FLORIANÓPOLIS
}

\author{
Fabrício Heinle Preigschadt \\ Faculdade de Tecnologia SENAI/SC em Florianópolis \\ Tiago Marques Lima \\ Faculdade de Tecnologia SENAI/SC em Florianópolis
}

\begin{abstract}
RESUMO: Este artigo apresenta uma pesquisa-ação que está sendo desenvolvida na Faculdade de Tecnologia SENAI/SC em Florianópolis, que tem como propósito construir, utilizar e avaliar uma plataforma para publicação de Webquest, tanto nos seus aspectos técnicos - o uso da tecnologia em si - quanto nas práticas pedagógicas nas quais os professores precisam publicar orientações para o desenvolvimento de trabalhos extraclasse. $\mathrm{O}$ artigo apresenta a proposta da pesquisa, o que já foi desenvolvido e argumenta da vantagem do professor utilizar uma ferramenta de tecnologia digital para publicação de orientações de trabalhos.
\end{abstract}

Palavras-chave: Webquest. Tecnologia digitais na educação. Práticas pedagógicas. 


\section{A TECNOLOGIA COMO INSTRUMENTO DE ENSINO E APRENDIZAGEM}

Em seu artigo "A introdução da informática no ambiente escolar" Lopes (2004) apud Jonassen (1996) sobre a tecnologia na aprendizagem, faz a seguinte classificação da relação da tecnologia e a aprendizagem:

1) Aprender a partir da tecnologia: neste caso a tecnologia é que apresenta o conhecimento, como se ela fosse o professor.

2) Aprender acerca da tecnologia: neste caso o objetivo é aprender sobre a tecnologia.

3) Aprender através da tecnologia: quando o aluno programa o computador para que ele faça as coisas.

4) Aprender com a tecnologia: quando a produção de conhecimento é realizada com o uso da tecnologia nos processo pedagógico. Assim, a tecnologia dá apoio ao processo ensino e aprendizagem.

Ao refletirmos sobre o uso do computador pelo professor, podemos nos remeter a dois contextos distintos: um é o uso do computador no cotidiano do professor fora da sala de aula, onde ele utiliza o computador para digitar suas provas, lançar notas, trabalhar com o diário eletrônico (quando há o uso de sistemas de informática acadêmicos), etc. 0 outro contexto é quando o professor utiliza o computador dentro da sala de aula, como recurso tecnológico que o ajuda na docência.

Utilizar o computador dentro da sala de aula, é difícil, mas pode facilitar ou também dificultar a vida do professor. Podemos fazer a seguinte classificação sobre o lugar de uso do computador e, de acordo com este lugar, o que ele pode facilitar ou dificultar a vida do usuário, como propomos no quadro 1. 
Quadro 1 - Computador como facilitador ou dificultador

\begin{tabular}{|c|c|c|}
\hline LUGAR DE USO & FACILITA QUANDO: & DIFICULTA QUANDO: \\
\hline $\begin{array}{l}\text { Fora da sala de } \\
\text { aula }\end{array}$ & $\begin{array}{l}\text { O professor sabe utilizar programas para } \\
\text { criação de provas, lançamento de notas, } \\
\text { etc. }\end{array}$ & $\begin{array}{l}\text { Não há dificultador neste caso, } \\
\text { a não ser o uso dos próprios } \\
\text { programas. }\end{array}$ \\
\hline $\begin{array}{l}\text { Dentro da sala } \\
\text { de aula }\end{array}$ & $\begin{array}{l}\text { O professor sabe utilizar o computador } \\
\text { como ferramenta na construção do } \\
\text { conhecimento, utilizando recursos como } \\
\text { programas para a educação (como o } \\
\text { Logo), objetos de aprendizagem, escrita } \\
\text { colaborativa e outras estratégias que } \\
\text { permitama construção do conhecimento. } \\
\text { O professor procurar conhecer e utilizar } \\
\text { ferramentas que podem auxiliá-lo no seu } \\
\text { trabalho. }\end{array}$ & $\begin{array}{l}\text { O professor não sabe utilizar } \\
\text { o computador para facilitar o } \\
\text { aprendizado. } \\
\text { O professor vê nas ferramentas } \\
\text { que pode utilizar um trabalho } \\
\text { a mais e não tem interesse em } \\
\text { utilizá-las. }\end{array}$ \\
\hline
\end{tabular}

Fonte: elaborado pelos autores

O que temos visto ocorrer, muitas vezes, é o professor dizer que utiliza a tecnologia como recurso importante no papel ensino-aprendizagem, mas na verdade ele a tem utilizado para que o aluno apenas "aprenda a partir da tecnologia" ou "aprenda acerca de tecnologia" quando, na verdade, julgamos importante que o aluno "aprenda através da tecnologia" ou "aprenda com a tecnologia".

Para que o aluno aprenda através/com a tecnologia, o professor precisa reformular algumas posturas antigas de mero "transmissor de conhecimento" e criar estratégias que facilitem o aprendizado.

Assim, apesar da dificuldade da criação das estratégias e do aprendizado que o professor precisa buscar no uso destes recursos, quando ele adquire maturidade suficiente para seu uso, o computador passa a facilitar o processo de aprendizagem e, conseqüentemente, está facilitando é o seu trabalho.

\section{USO DOS COMPUTADORES PELOS PROFESSORES}

Uma pesquisa feita por Fantin (2010) nas escolas municipais de Florianópolis/SC revelou que $95 \%$ dos professores entrevistados possuem computador, $72,5 \%$ deles acessam a internet todos os dias, mas $82 \%$ disseram que não têm conhecimento para utilizar o computador em suas práticas pedagógicas. 
Para Silva, Souza e Correa (2010, p.11) "incorporar o uso das tecnologias digitais na Educação é um processo lento e sobretudo não é um processo que não funcionaria se fosse de cima para baixo, ou seja, se fosse uma decisão única e exclusivamente da instituição".

É preciso que haja parceria entre a escola e o professor, tanto no sentido do incentivo para o uso das tecnologias nas práticas pedagógicas, quanto na disponibilização de recursos para que isto seja possível. Parceria significa, antes de tudo, que não haja imposição da instituição e nem decisão unilateral dos docentes do uso ou não das tecnologias, mas um diálogo de como ambos (instituição/professor) podem fazer o melhor uso dos recursos, de acordo com o que cada escola dispõe.

\subsection{Webquest}

Uma webquest é uma proposta de atividade com o máximo de instruções para que a tarefa seja realizada a contento. É útil, portanto, quando um professor precisa propor ao aluno que desenvolva um trabalho escolar. Foi criada por Dodge (1997) e suas partes constitutivas pode ser resumida no quadro 2 .

Silva (2010, p.10) afirma que:

se solicitarmos aos alunos que façam uma pesquisa escolar sobre determinado tema, dando a eles somente o tópico/assunto a ser pesquisado, sem nenhuma orientação, é fato que a grande maioria prefere fazer uma cópia de textos disponíveis na internet e entregar ao professor. Quando um professor age assim, ou seja, dá uma tema para um trabalho e não orienta, ele inconscientemente está pedindo que isso aconteça.

Assim, esta estrutura de webquest proposta por Dodge (1997) serve de instrumento para que o professor tenha condições de orientar melhor o aluno acerca da atividade proposta e para que o aluno tenha as informações necessárias não somente para realizar a atividade, mas também de como ele será avaliado.

Quadro 2 - Partes constitutivas de uma Webquest

\begin{tabular}{|l|l|}
\hline \multicolumn{1}{|c|}{$\begin{array}{c}\text { Parte da } \\
\text { webquest }\end{array}$} & \multicolumn{1}{c|}{ Objetivo } \\
\hline Introdução & $\begin{array}{l}\text { A introdução tem o propósito de fazer com que o aluno conheça o tema } \\
\text { em questão. Neste caso, o professor deve fazer uma fundamentação, situar } \\
\text { historicamente o tema e fazer algumas referências para que, a partir disto, } \\
\text { o aluno tenha condições de caminhar sozinho. }\end{array}$ \\
\hline Tarefa & $\begin{array}{l}\text { A tarefa é justamente a proposta de trabalho. Ela deve ser desafiadora, no } \\
\text { sentido de que o aluno não encontro respostas prontas ao pesquisar na } \\
\text { internet, mas que possa dialogar com o tema a partir do que o professor } \\
\text { propõe. }\end{array}$ \\
\hline
\end{tabular}




\begin{tabular}{|l|l|}
\hline Processo & $\begin{array}{l}\text { O processo consiste em uma apresentação de como o trabalho deve ser } \\
\text { realizado. Se em grupo ou individual, entre outras informações relevantes } \\
\text { de como fazer. }\end{array}$ \\
\hline $\begin{array}{l}\text { Fontes } \\
\text { informação }\end{array}$ & $\begin{array}{l}\text { São as referências, sejam elas impressas ou online. Pode-se utilizar hiperlinks } \\
\text { com fontes na internet (textos, vídeos) e outros materiais. }\end{array}$ \\
\hline Avaliação & $\begin{array}{l}\text { Como a tarefa será avaliada. Deve-se procurar ser o mais transparente } \\
\text { possível, ou seja, deixar as regras de avaliação bem claras e objetivas. }\end{array}$ \\
\hline Conclusão & $\begin{array}{l}\text { Considerações finais sobre o tema. } \\
\text { Créditos }\end{array}$ \\
\hline
\end{tabular}

Fonte: elaborado pelos autores.

\subsection{A pesquisa com webquest no SENAI/SC em Florianópolis}

Thiollent (2004) que uma pesquisa-ação é um tipo de pesquisa que, com estreita cooperação entre pesquisador e pesquisado, objetiva a solução de um problema coletivo.

A pesquisa com Webquest na Faculdade de Tecnologia SENAI/SC em Florianópolis tem cinco alunos bolsistas dos artigos 170 e 171, além de um professor coordenador.

Como a proposta da pesquisa é contar com a ajuda dos professores e alunos usuários da plataforma de Webquest, trata-se uma pesquisa-ação.

As fases da pesquisa são:

Inicial: março de 2010 a janeiro de 2011.

Intermediária: fevereiro a julho de 2011.

Conclusiva: agosto de 2011 a fevereiro de 2012.

$\mathrm{Na}$ fase inicial um protótipo da plataforma já foi construído e disponibiliado para as primeiras publicações de Webquest, no endereço http://webquest.ctai.senai.br. Neste momento da fase inicial estão sendo investigadas, através do uso de questionários, que ainda se encontram em processo de reelaboração, as práticas pedagógicas com uso de Webquest.

$\mathrm{Na}$ fase intermediária a versão final da plataforma será disponibilizada para dar continuidade ao uso e à investigação das práticas pedagógicas advindas deste uso.

Na fase conclusiva serão analisadas as várias ações por parte dos professores que publicaram atividades na Webquest e, posteriormente, a mesma será disponibilizada para as escolas públicas. 


\subsection{A construção do ambiente WQS SENAI}

A plataforma WQS SENAI foi construída com o uso do software Joomla, de uso gratuito. Para os alunos e a comunidade em geral, que utilizam o ambiente para consultar Webquest e, portanto, não precisam postar o Webquest, o acesso é direto, sem a necessidade de efetuar o login no ambiente.

Para os professores que publicam uma Webquest, é necessário solicitar ao administrador do sistema a criação e um usuário e senha para acesso. Com este usuário e senha, o professor pode publicar Webquest, excluir e alterar as suas Webquests.

A figura 1 apresenta a tela inicial da Webquest. No exemplo, vê-se que um professor digitou o login para entrada . Caso seja um aluno ou alguém da comunidade externa, basta cliclar em Webquests para visualizar aquelas que foram publicadas.

Figura 1 - Tela de entrada no ambiente

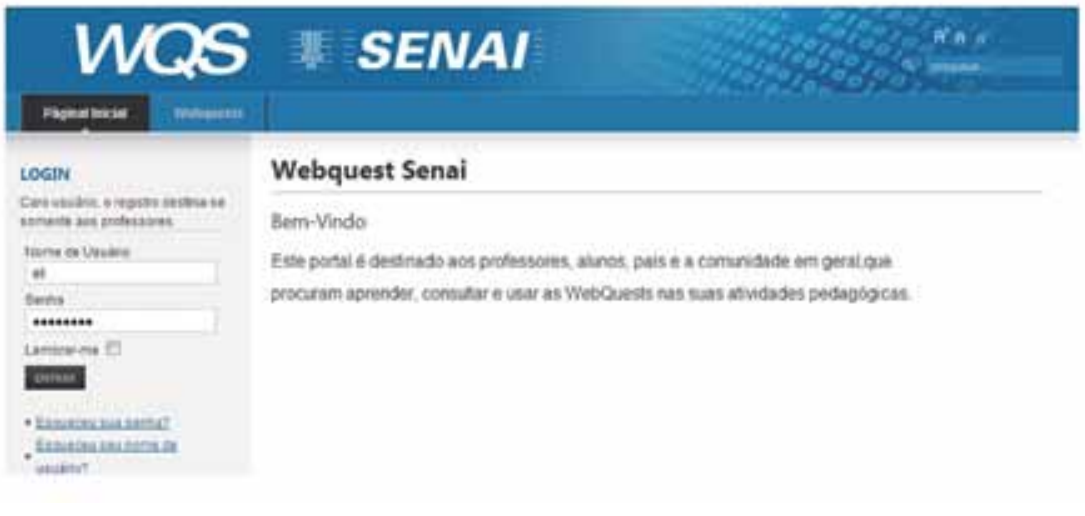

Fonte: http://webquest.ctai.senai.br

O gerenciamento de Webquest é bem simples, pois permite criar, remover e editar, como se vê na figura 2. 
Figura 2 - Tela de gerenciamento de Webquest

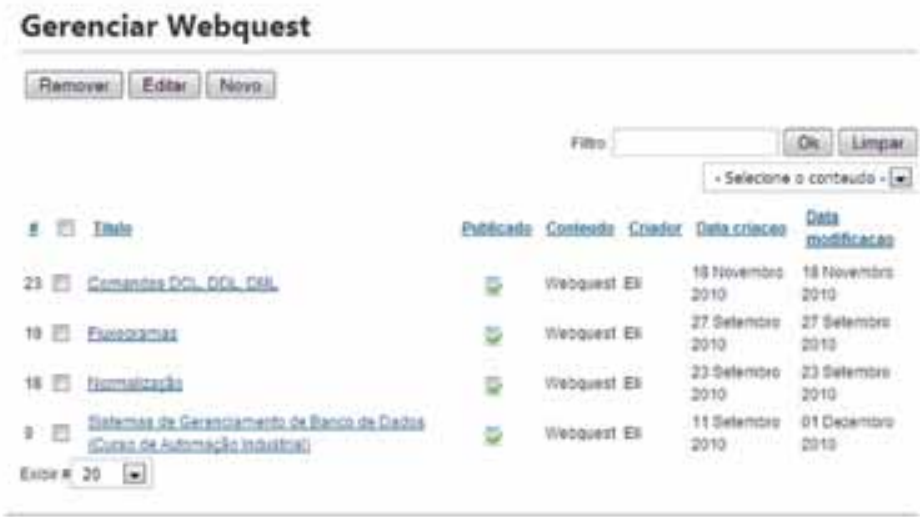

Fonte: http://webquest.ctai.senai.br

A criação de um Webquest é um processo simples, pois na escolha de da opção "Novo" na tela de gerenciamento (Figura 2), as telas de criação disponibilizam um editor de textos para o usuário criar cada etapa da Webquest, como se vê na figura 3. É possível também copiar e colar de algum editor de textos para este, caso o usuário já tenha os dados digitados.

Figura 3 - Criação de uma nova Webquest

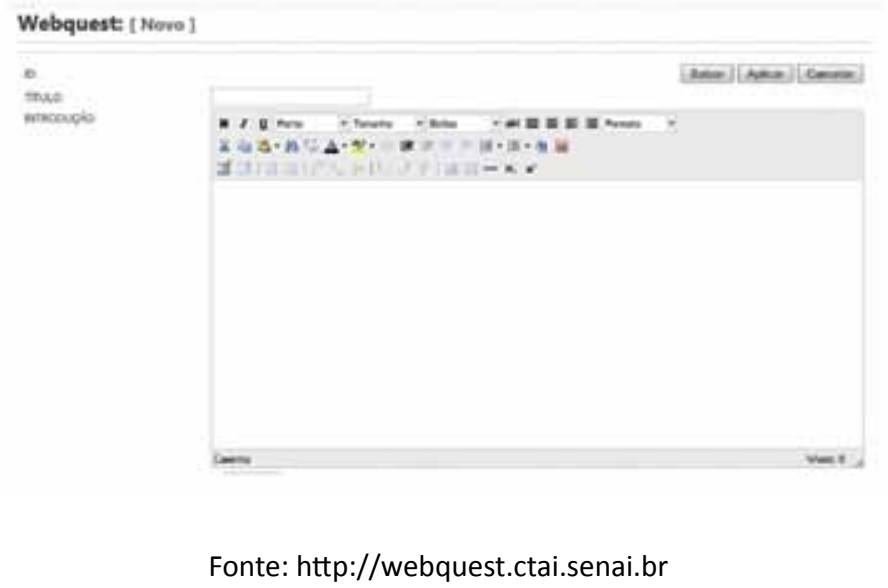

Tanto os usuários cadastrados no sistema (geralmente os professores) quanto os demais, podem visualizar Webquest cadastrada, como se pode ver na figura 4. 


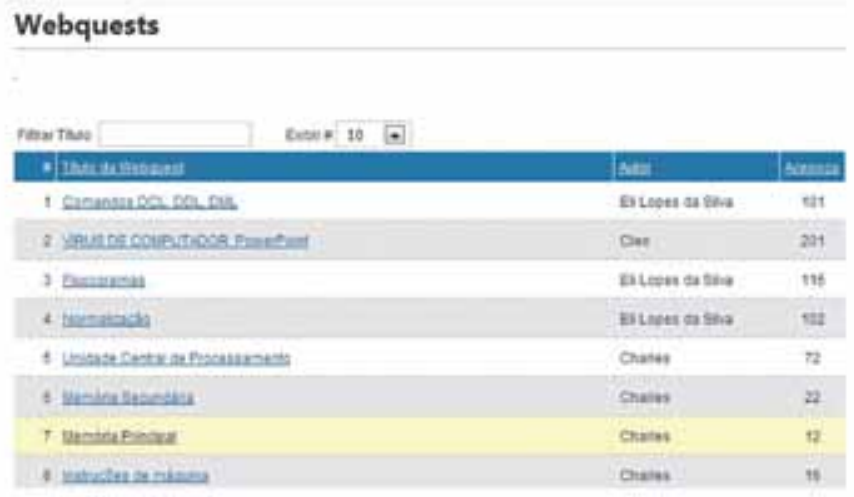

Fonte: http://webquest.ctai.senai.br

Ao clicar em uma Webquest publicada, a mesma é disponibilizada e um menu de nevagação, de fácil acesso e manuseio é disponibilizado (introdução, tarefa, etc), conforme figura 5 .

Figura 5 - Navegação em uma Webquest

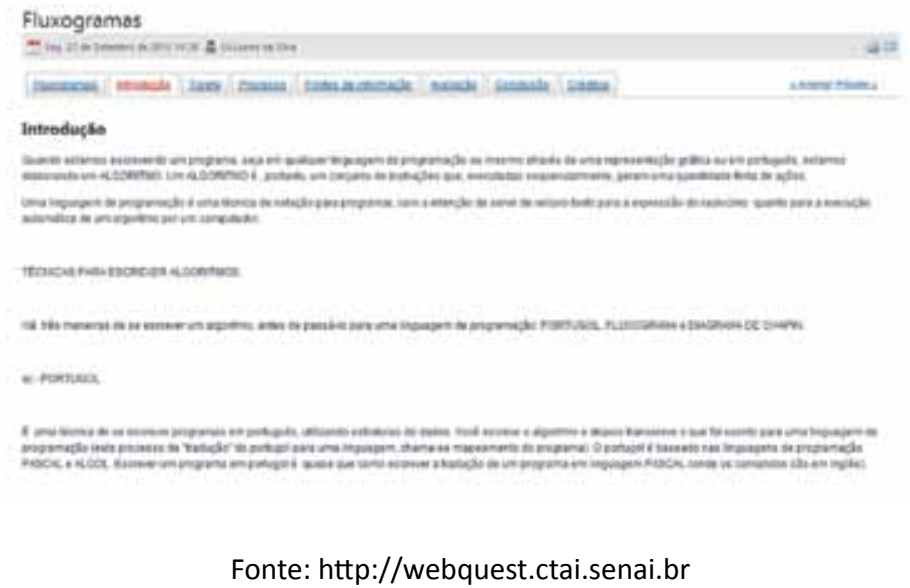

\section{CONCLUSÃO}

Os professores muitas vezes desconhecem os diversos recursos tecnológicos digitais que poderiam auxiliá-los em suas práticas pedagógica, sendo a Webquest um destes recursos.

Como apontado na investigação desta pesquisa, muitas vezes o desconhecimento se tanto no que diz respeito ao recurso em si, como na dificuldade operacional de publicar um Webquest.

A plataforma que, embora esteja em construção, mas já está em uso, mostrou-se ser muito fácil de ser utilizada e, quando em sua versão definitiva, certamente se constituirá 
uma excelente ferramenta de apoio ao processo de ensino e aprendizagem, no que diz respeito à possibilidade dar ao professor uma boa ferramenta que permitirá a ele publicar orientações das atividades extra-classe propostas aos alunos.

A ideia de uma Webquest é relativamente simples, um complicador seria a publicação na Web, sobretudo para professores que não necessariamente tenham o conhecimento da tecnologia envolvida para publicação. A plataforma WQS SENAI vem suprir esta lacuna e possibilitar ao professor este ganho pedagógico do uso deste tipo de recurso.

\section{CONSTRUCTION, USE AND EVALUATION OF A PLATFORM FOR PUBLICATION OF THE WEBQUEST SENAI / SC IN FLORIANOPOLIS}

ABSTRACT: This article presents an action research that is being development at the Faculty of Technology SENAI / SC Florianópolis, which aims to build, operate and evaluate a platform for publication of Webquest, both in its technical aspects - the use of technology itself - as in pedagogical practices in which teachers need to publish guidelines for the development of extra-class work. The article presents the research proposal, which has already been developed and argues for the advantage that the teacher has a tool when using digital technology to publish directions of work.

Keywords: Webquest. Digital technologies in Education. Pedagogical practices.

\section{REFERÊNCIAS}

DODGE, Bernie. Some Thoughts About WebQuests. San Diego State University (SDSU). 1997. [Publicação on-line]. Disponível em: <http://webquest.sdsu.edu/about_ webquests.html>. Acesso em 21 jun. 2009.

FANTIN, Mônica. Um olhar sobre os consumos culturais e os usos das mídias na prática docente. In: Encontro de Pesquisa em Educação da Região Sul - ANPED SUL, 8. , 2010, Londrina. Anais... Londrina: Universidade Estadual de Londrina, 2010.1CD-ROM.ISSN 2178-0374

LOPES, José Júnio. "A introdução da informática no ambiente escolar". 2004. Disponível em: <http://www.clubedoprofessor.com.br/artigos/artigojunio.htm.> Acesso em: 29 nov. 2010.

SILVA, Eli Lopes da. Webquest como prática pedagógica: pesquisa-ação em um curso de graduação no SENAI Florianópolis. In: Encontro de Pesquisa em Educação da Região Sul 
- ANPED SUL, 8. , 2010, Londrina. Anais... Londrina: Universidade Estadual de Londrina, 2010.1CD-ROM.ISSN 2178-0374.

SILVA, Eli Lopes da; SOUZA, Diney Domingos de; CORRÊA, Alexandre Bastos.

Construção, uso e avaliação de uma plataforma para Webquest baseada no Joomla: pesquisa-ação na Faculdade de Tecnologia SENAI Florianópolis. In: COLÓQUIO NACIONAL DE PESQUISA EM EDUCAÇÃO, 7., 2010, Belo Horizonte. Anais... Belo Horizonte: Editora UFSJ, 2010. ISBN 9788588414600.

THIOLLENT, Michel. Metodologia da pesquisa-ação. 13.ed. São Paulo: Cortez, 2004. 